\title{
De bellas durmientes y putas tristes
}

\section{Federico PATÁN \\ Universidad Nacional Autónoma de México}

Desde luego, hay muchas maneras de escribir sobre el otoño e incluso el invierno. Quiero decir, con esto, en términos de la existencia humana. Yasunari Kawabata (18991972) lo hizo en 1961. Gabriel García Márquez (1927) se adentró por ese camino en el 2004, ambos en una novela corta. Kawabata nombró a la suya La casa de las bellas durmientes y García Márquez Memoria de mis putas tristes a la suya. Hay razones convincentes para suponer que el colombiano estaba rindiendo homenaje a su colega japonés, siendo una de ellas el que usara una cita de Kawabata como epígrafe de su texto. Pero hay más. Como dije, ambos relatos examinan la ancianidad y, agregaré ahora, el intento de disminuir mediante la compañía de prostitutas la consiguiente tristeza de saberse viejo. Por tanto, ancianidad y prostitutas. Sin embargo, como es de suponer, ese punto de arranque común da pie a dos acercamientos diferentes, que manifiestan puntos de vista contrastantes respecto a la vida y a los modos específicos de escribir sobre el asunto.

Por ejemplo, el título dado a las obras. La casa de las bellas durmientes parece venir de una atmósfera poética, con sus delicadas sugerencias de cuento popular. En una primera lectura, todo habla de amabilidad e incluso de buena voluntad. El título dado a su texto por García Márquez es de naturaleza más abrupta a causa de dos palabras: "putas" y "tristes". Pero además habla de un mundo diferente, en el cual no se disfrazan las condiciones de una cierta vida; antes al contrario, se la describe con franqueza, sin evocaciones gentiles, bien que la prosa del autor tienda a lo poético. El título japonés se abre, antes de iniciarse la lectura del texto, a varias interpretaciones. El otro es menos generoso en sugerencias. Esto ¿hace que el texto de Kawabata sea de un realismo menor que el de García Márquez? De ninguna manera. Simplemente nos enfrentamos a dos maneras de describir la realidad, siendo la del japonés de naturaleza más introspectiva pese, paradoja al calce, estar presentada por un narrador heterodiegético. Contada en primera persona, la obra de García Márquez se queda más en la superficie de los acontecimientos descritos. Procurar descubrir la razón de esto es el propósito del presente ensayo.

De examinarse las líneas iniciales de cada narración, de inmediato se hacen obvias las diferencias. Voy al texto más antiguo. Dice: "No debía hacer nada de mal gusto, advirtió al anciano Eguchi la mujer de la posada. No debía poner el dedo en la boca de 


\section{$132 \square$ DE BELLAS DURMIENTES Y PUTAS TRISTES}

la muchacha dormida ni intentar nada parecido" (Kawabata: 9). Con inicio in medias res, la narración sitúa al lector en una escena ya en movimiento, ofreciéndole bastantes datos importantes: el nombre del protagonista, que es anciano y que debe comportarse adecuadamente, lo cual significa el peculiar consejo de no introducir el dedo en la boca de la chica, consejo que nos extrañaría oír en nuestra cultura. El propósito de la visita nos lo sugieren muy indirectamente, justo con base en el consejo mencionado. Cuando paso a los renglones iniciales de García Márquez ¿con qué me encuentro? "El año de mis noventa años quise regalarme una noche de amor loco con una adolescente virgen" (García Márquez: 9). He aquí la expresión directa de un deseo que es, al mismo tiempo, expresión de un modo de concebir la vida: hay en el mundo adolescentes a mi disposición por el mero hecho de pedirlas y, por tanto, quiero una como regalo de cumpleaños. El que la afirmación venga de un hombre muy anciano la hace más chocante. El viejo parece afirmar: mi sociedad está construida de este modo y me limito a sacar provecho de ello, sin más consideraciones.

Acaso tal sea el propósito de la trama: introducir los acontecimientos con una idea chocante e incluso repelente para entonces, con prudente lentitud, modificar la perspectiva del anciano respecto a su decisión inicial. Sin cambiar su posición moral, el personaje central se redime con el sencillo expediente de enamorarse, enamorarse locamente, de Delgadina, como termina por llamar a la muchachilla de catorce años que le presentan en la "casa clandestina" de Rosa Cabarcas. El amor, entonces, como excusa moral para una relación un tanto extraña. Lo cual establece una diferencia con la novela corta de Kawabata, donde el amor queda subordinado a otros temas, centrada como se encuentra la historia en examinar la necesidad de enfrentarse a las consecuencias de la vejez. Así que, partiendo de la misma premisa, los dos autores toman diferentes caminos. En el relato del colombiano el narrador homodiegético explica su intención: pasar una noche de amor loco con una adolescente virgen. Pero ¿qué quiere decir con amor loco? La deducción lógica es traducir las dos palabras sencillamente como "hacer el amor" y, desde luego, quitar la virginidad a un cuerpo complaciente por obligación. Pero entonces, lo dije ya, el anciano se enamora de la jovencita poco a poco. Y, por razones muy distintas a las de Eguchi, respeta esa virginidad.

Así que, en realidad, el libro de García Márquez es una historia romántica, de sabor un tanto peculiar dada la edad del protagonista. El narrador nos solicita que suspendamos nuestra incredulidad, y aceptemos como posible que Delgadina, con sus catorce años, termine enamorándose de un hombre de noventa. Nos mostramos dispuestos a complacerlo, aunque en bastantes ocasiones resulta bastante difícil, en especial si partimos de que se describe a sí mismo como "feo, tímido y anacrónico" (García Márquez: 10), bien que haya una dosis de ironía en esto. Ocurre, además, que en tanto lectores tendemos a olvidar la edad del personaje. Será porque ocasionalmente se comporta como alguien más joven, y los noventa años terminan por ser algo que él dice tener. Si, a modo de comparación, vamos a la Lolita (1955) de Vladimir Nabokov (1899-1977), es de preguntarse por qué esta novela es del todo convincente, viniendo a mientes como una de las respuestas que Lolita no muestra un amor apa- 
sionado por Hubert Hubert. Otra respuesta, la edad de éste. En la trama creada por García Márquez el protagonista confiesa que Delgadina es "el primer amor de mi vida a los noventa años" (ibid.: 62), ya que todas las relaciones anteriores se limitaron al juego sexual. Con avances muy lentos el anciano progresa en su conquista amorosa de la jovencita; con avances muy lentos las caricias incrementan su intensidad y su variedad. Muy pronto "ella me respondió con vibraciones nuevas en cada pulgada de su piel" (ibid.: 72) y, finalmente, el anciano comprende que se está muriendo de amor. Como es lo adecuado y frecuente antes de un desenlace feliz, la pareja habrá de separarse, en este caso debido a razones externas. La separación le permite al protagonista comprender cuán hondo es su enamoramiento de la adolescente, intentar encontrarla y, a fin de cuentas, triunfar en la empresa. Hacia la conclusión del relato Rosa Cabarcas le dice: "esa pobre criatura [Delgadina] está lela de amor por ti” (ibid.: 109). Como él se propone vivir hasta los cien años e incluso más allá, no parece haber problema alguno.

Es del todo fácil gozar la narración de García Márquez. La trama avanza con fluidez, ateniéndose a los rasgos generales de una novela romántica; abundan los personajes y son agradables, pues ninguno de ellos padece una naturaleza sombría; la acción no está confinada a un solo lugar, ya que el protagonista se desplaza de su casa al periódico donde aún trabaja y enseguida adonde Rosa Cabarcas. Los diálogos son ingeniosos y abundan las situaciones humorísticas, de modo que el drama implícito nunca corre el riesgo de caer en los oscuros laberintos de la tragedia. Por ejemplo, aquel de la ancianidad. Es uno de los hilos entretejidos a la trama y, tengo la seguridad, deriva del libro de Kawabata y, aquí estoy meramente suponiendo, de las relaciones del autor con su propia edad. Pero, considero necesario insistir, García Márquez se acerca al tema con una fuerte dosis de optimismo y buen humor. La cuestión central es descubrir en qué momento se tuvo conciencia de la edad. Echando la vista atrás, el protagonista piensa que ocurrió hacia sus cincuenta años. "Fue la primera vez que pensé en mi edad en términos de vejez, pero no tardé en olvidarlo" (ibid.: 14). Olvidarlo se vuelve cada vez más difícil según se acumulan los años, de modo que al llegar a los noventa comienza a "contar minuto a minuto los minutos de las noches que me hacían falta para morir" (33). Pero lo dice sin amargura.

Pero entonces ¿cómo luchar contra la seguridad de cada vez tener menos tiempo por vivir? Olvidándose de la ancianidad. ¿Cómo olvidarse? Abriéndole perspectivas a la vida. ¿Cómo lograrlo? Enamorándose. Y así vuelvo a los renglones iniciales del libro: celebrando el haber llegado a una edad extrema mediante una muchacha extremadamente joven, tal vez porque la sensación de juventud sea contagiosa. Sea como fuere, el libro de García Márquez cierra con un obvio espíritu de triunfo. El optimismo está ausente en el texto de Kawabata. A lo largo de la trama se da una sensación opresiva de vacío, que penetra en la existencia según se avanza hacia la decrepitud. Se describe esa sensación opresiva, aparte de la situación espiritual de Eguchi, mediante las estrechas habitaciones donde se da la acción. Como expliqué anteriormente, el personaje de García Márquez se desplaza por la ciudad en la que vive, y ese movimiento da a la 


\section{$134 \square$ DE BELLAS DURMIENTES Y PUTAS TRISTES}

historia una sensación de libertad. En Kawabata todo es sofocante. Una cierta sensación de gozo presente en el texto colombiano está ausente del todo en el japonés.

En ambas narraciones hay un lento acercamiento a la sensación de senectud, que en el texto de García Márquez se ve derrotada por el optimismo final. No ocurre así en Kawabata, donde la comprensión última va en dirección opuesta, aunque el protagonista es más joven que el de García Márquez: meros 67 años. Y pese a ello, he aquí sus pensamientos al comienzo de la narración: "El hombre que le habló a Eguchi de la casa era tan viejo que ya había dejado de ser hombre" (Kawabata: 13). Palabras duras, que describen la profunda sensación de desolación que el personaje tiene, aunque la cita pueda referirse asimismo a la impotencia sexual. Agréguense a lo anterior las siguientes palabras: "La fealdad de la vejez lo estaba acosando" (idem.). Hay una sensación de pérdida inmediata, de que la vida nos hace de lado. Y como la existencia se permite una trampa así de sucia, el hombre debe contraatacar. ¿Cómo? Mediante una jovencita. Pero siguen apareciendo diferencias entre las dos narraciones. Váyase a los pensamientos de Eguchi: "Pero ¿podía haber algo más desagradable que un viejo acostado durante toda la noche junto a una muchacha narcotizada, inconsciente" (idem.). De inmediato se perciben las contrastantes posiciones éticas. En García Márquez no hay preocupación por cuestiones morales: Deseo proporcionarme un agradable regalo de cumpleaños y nada más merece consideración. En Kawabata siempre está presente una preocupación moral.

¿Por qué elegir una joven? En García Márquez no hay explicación directa pero, como ya dije, es muy posible deducir la posibilidad de volverse espiritualmente más joven mediante el contagio. Eguchi, dado todo el tiempo a consideraciones graves sobre la ancianidad, aborda el problema directamente: al pagar la compañía de una muchacha "¿Abandonaría a los ancianos la tristeza, la fealdad, la indiferencia de la vejez, se sentirían llenos de las bendiciones de una vida joven?” (ibid.: 44). Eguchi medita en torno del problema y a lo largo de toda la novela sigue la misma dirección: pensar cuál es el significado e incluso el propósito de la vejez. La diferencia es notable con García Márquez, quien opera más en la dirección de una historia amorosa. Desde luego, una historia de amor que le permite al protagonista derrotar su sensación de ancianidad. Kawabata aprovecha la relación superficial con las distintas muchachas para establecer una inevitable idea de acabamiento, de que la muerte aguarda al extremo del camino. Al final, Eguchi acepta que es un anciano, que le restan simplemente unos cuantos años más de vida triste. He aquí la diferencia principal entre las dos obras. La de García Márquez es de naturaleza más ligera porque trabaja con tono menos pesaroso el problema filosófico de la vejez.

Ahora, paso a los protagonistas. El de García Márquez es un periodista jubilado, de noventa años, que está escribiendo "esta memoria de mi grande amor" (García Márquez: 12). Es bastante ingenuo describiéndose: un ser solitario, acostumbrado a la compañía de prostitutas. No tiene esposa ni hijos. Satisface sus necesidades pagándose compañía o mediante algunas aventuras en las cuales obligó a sus acompañantes a recibir un pago. Incluso da en mencionar la cifra de mujeres distintas que tuvo hasta llegar a los 
cincuenta: 514. Más al punto, escribió un diario de sus encuentros con ellas, donde especifica la edad de la compañera, el lugar del encuentro, las circunstancias de tal encuentro y lo que él describe como el modo de hacer el amor. El lector se pregunta por la razón de tal hábito. Una respuesta posible es que tal memoria escrita es una especie de comprobación de que ha vivido, no importa cuan faltos de importancia los sucesos. Al mismo tiempo, es un documento de cuan poco le dio la existencia. Según sus palabras: "Eso fue todo cuanto me dio la vida y no he hecho nada por sacarle más" (ibid.: 19). Así pues, la soledad y la lenta aceptación de la vejez, el sexo sustituyendo al amor hasta el momento en que Delgadina aparece con su presencia liberadora.

El panorama es diferente con Eguchi. En primer lugar, está casado y tiene descendencia. Poco se nos dice acerca de la esposa y todo nos llega mediante los pensamientos del protagonista, de modo que es un enfoque subjetivo. Sea como fuere, un hecho importante viene a Eguchi como una revelación súbita: "En realidad, su primera mujer había sido su esposa" (Kawabata: 96). Luego, aparte de la esposa, hubo un cierto número de coqueteos y aventuras, cada uno de ellos recordado con tristeza, y no porque fueran necesariamente insatisfactorios sino porque traen a mientes la condición actual del narrador. Si volvemos a García Márquez, el protagonista da la cifra de mujeres con las que tuvo relaciones, pero nada más sabe de ellas el lector. El personaje de Kawabata es más generoso en sus recordaciones e, incluso cuando oculta el nombre de la mujer, trae a la memoria, y por tanto a la atención del lector, una cierta condición psicológica de cada pareja. Por ejemplo, la esposa de un ejecutivo que lucha contra el insomnio contando los hombres por los que le hubiera gustado ser besada. Un juego sencillo, que incluso pudiera ser inventado piensa Eguchi, con lo cual revela mucho acerca de la mujer. Pero el recuerdo deriva en lo siguiente: "no obstante, el hecho de ser utilizado a sus espaldas por la mente de una mujer de edad mediana resultaba bochornoso" (Kawabata: 22-23), sin que Eguchi piense que está utilizando a una joven con propósitos muy personales. Por tanto, es obvio que el texto de Kawabata se encuentra más inmerso en meditar cuestiones de naturaleza ética, mientras que el de García Márquez las aborda con un espíritu demasiado amable.

Uno de los principales intereses temáticos, lo he afirmado ya con insistencia, es la vejez. Eguchi, tan dado a las meditaciones que pudiera considerarse al relato como una inmersión en la mente del personaje, llega a la siguiente idea: "Una vida joven se formaba en la mujer, dando a Eguchi una conciencia todavía mayor de su propia edad" (ibid.: 62). Delgadina es la excusa que García Márquez da a su protagonista para que se olvide de la vejez, para concederle una perspectiva optimista del futuro. En Kawabata todo es pesimismo. Tanto así que muy cerca de la conclusión del texto Eguchi se confiesa: soy viejo.

¿Por qué revelación al parecer así de súbita? Porque las visitas a la casa de las bellas durmientes le permite meditar en torno de tal condición. Meditar lo obliga a reunir pruebas sobre su situación presente y esa acumulación lo conduce a la aceptación definitiva de su edad, sobre todo de la espiritual. En la página final el narrador hace un comentario al parecer meramente descriptivo: "Eguchi sintió por primera vez que el frío 
lo penetraba" (ibid.: 99). Es un frío del cuerpo, desde luego, pero también del espíritu. Varias razones dan presencia a tal frío: el amontonamiento de recuerdos sobre relaciones fracasadas, la innegable presencia de la vejez, la defunción de otro cliente de la casa, la muerte accidental de una de las bellas durmientes. Con ello, otro tema capital aparece en la trama: el de la muerte. Es una posibilidad que se menciona en varias ocasiones en el texto de García Márquez, pero sin que haya mucha preocupación en el protagonista. Es una presencia derrotada finalmente por ese optimismo ya tan mencionado.

Citaré del relato de Kawabata. Hacia la mitad del mismo Eguchi comienza a pensar en la muerte; en uno de los casos particulares da en considerar lo siguiente: "Le atraía mucho la idea de dormir un sueño semejante a la muerte junto a una muchacha drogada hasta parecer muerta" (ibid.: 57). Antes de esto, ha especulado sobre si ha tenido nostalgia de la muerte. De pronto, el sentido profundo de las chicas dormidas brota en la superficie del texto: son una representación metafórica de la muerte y la muerte el tema real del libro, quedando la vejez como un recordatorio de la cercanía de tal fin. E incluso del suicidio. Porque en uno de sus diálogos con la encargada de la casa, Eguchi interroga sobre la posibilidad de matarse para solucionar la situación. Acaso esté simplemente jugando con la idea, pero el lector nunca puede estar seguro de ello. El personaje incluso llega a explorar la posibilidad de matar a una de las muchachas dormidas, para no irse solo. Con absoluto desdén por las cuestiones morales del caso, la encargada le dice: adelante, estamos para complacerlo. La mujer se limita a cumplir sus obligaciones. Es un momento de profundo sobresalto para el lector. Eguchi continúa con sus meditaciones, y termina por preguntarse: en tales condiciones ¿qué importancia tienen la inteligencia, la cultura o la barbarie? Dadas las circunstancias, nada fácil es responder a esto. Kawabata parece deleitarse en poner al lector ante cuestiones de esa naturaleza. Son cuestiones más bien ausentes en el libro de García Márquez o, por lo menos, de presencia bastante disminuida. Claro está, es su modo de abordar el tema y tiene toda la libertad artística para hacerlo, pero al lado del relato de Kawabata el suyo parece de menor densidad.

El párrafo anterior abre a discusión otro aspecto: las encargadas de las respectivas casas. He mencionado que en García Márquez la dueña de la casa clandestina tiene nombre: Rosa Cabarcas. Por años ha mantenido relaciones con el protagonista, primero como prostituta, luego proporcionándole servidoras y a partir de cierto momento como amiga. Sus conversaciones tienen la fluida confianza de aquellos cuya relación es sólida. Representa el tipo de personaje que es de suponer en tal profesión: ninguna profundidad en su modo de expresarse, siempre de espíritu práctico, dispuesta a ayudar a los clientes en lo que pueda ofrecérseles. Eso sí, muestra simpatía e incluso empatía por el anciano de noventa años. Se la introduce en el relato como un personaje imprescindible, pues sin ella la trama no funcionaría. En Kawabata la encargada se responsabiliza de la casa, pero no es la dueña. Mera empleada, se la mantiene anónima a todo lo largo del relato y es obvio que Eguchi la conoce al comienzo del libro. Poco a poco establecen algo parecido a una amistad y poco a poco ella comienza a revelarse ante Eguchi. No en el sentido de hablar de sí misma, sino en aquel otro de comentar los sucesos de la 
trama. Tanto así que Eguchi le pregunta: “¿Acaso empieza a emerger la mujer que hay en usted?" (ibid.: 71). Ella se limita a una sonrisa sarcástica y a la siguiente respuesta perceptiva: "Me imagino que a lo largo de los años usted habrá hecho llorar a muchas mujeres" (idem). De esta manera, Kawabata se atiene al propósito central de indagar en el sentido de la vejez y de la muerte. La mujer puede ser un tanto desagradable por su obediencia a las obligaciones impuestas por su oficio, pero es un desagrado que va con la naturaleza convincente del personaje. Parte de la verosimilitud de esta mujer proviene de un hecho muy sencillo: bajo la frialdad de conducta que ella misma se impone, el lector percibe un ser humano capaz de tener conflictos interiores. Rosa Cabarcas es toda ella optimismo y transparencia. La anfitriona perfecta con quien echarse un trago.

El efecto soleado que el relato de García Márquez crea surge en otro aspecto de la narración: los ámbitos en que ocurre la acción. Como ya dije, Kawabata mantiene la historia dentro de dos cuartos pequeños, muy desnudos de moblaje, que Eguchi acepta tal y como están. Excepto cuando las analepsis, la acción se mantiene puertas adentro, lo cual propicia una atmósfera de confinamiento que se corresponde muy bien con el conflicto psicológico del protagonista. En García Márquez no se da tal sensación de aprisionamiento. Diría yo que, al contrario, hay un aire de libertad, expresado en los desplazamientos del personaje. Pero incluso cuando está puertas adentro con la muchacha se respira libremente, en parte debido a que el protagonista trae al cuarto adornos para personalizarlo. Eguchi se encuentra siempre en territorio extranjero, mientras que en García Márquez se da una lenta conquista del local visitado.

En el texto de Kawabata hay un elemento muy presente en toda su narrativa: sonidos, en especial aquellos de la naturaleza. En su discurso al recibir el Premio Nobel dijo que daba enorme importancia a ciertas imágenes. "The snow, the blossoms, words expressive of the seasons as they move one into another, include in the Japanese tradition the beauty of mountains and rivers and grasses and trees, of all the myriad manifestations of nature, of human feelings as well" (Gessell: 280). Desde luego, ocurriendo la trama puertas adentro, La casa de las bellas durmientes tiene sus limitaciones en tal sentido. Aun así, el sonido de las olas y aquel del viento cumplen un papel metafórico en la trama. Cuando la encargada menciona el sonido de las olas al comienzo del texto, Eguchi pregunta ¿qué olas? Gradualmente, comienza a tomar conciencia de ellas y, también gradualmente, comienza a darles un significado. Y además está el viento, que trae consigo el sonido del invierno, un recordatorio de la edad que Eguchi tiene. Las olas se relacionan con la atracción que el personaje siente por las jóvenes durmientes, ya que aumentan su rugido según el corazón de Eguchi incrementa su ritmo. Pero se trate de olas o viento o lluvia, siempre pertenecen al otoño o al invierno, con lo cual expresan la condición espiritual y física del protagonista.

Desde luego, entre ambas novelas cortas hay muchos aspectos en común, ya que García Márquez derivó la suya de Kawabata. La cuestión central, desde cualquier punto de vista, es que ambos protagonistas son ancianos y sienten la presión de la senectud. El segundo aspecto es que ambos intentan compensar tal presión visitando a una jovencita. Tercera similitud, en los dos casos hay una mujer que proporciona las chicas. Cuarto 
punto, la muerte de otro cliente, lo que recuerda a los personajes su propia mortalidad. Pero pienso que las similitudes se dan en aspectos superficiales y las diferencias en la profanidad de manejo de tales elementos. Tengo para mí que la principal es aquella del tono. El texto de García Márquez es de naturaleza soleada, optimista y está lleno de buen humor. El de Kawabata se encuentra inmerso en una sensación de pérdida, de tristeza a causa de la edad, de la creciente presencia de la muerte. García Márquez opta por una improbable historia de amor; el amor en Kawabata es siempre una posibilidad, nunca algo real. García Márquez describe el aspecto sexual abiertamente; Kawabata opta por las insinuaciones con el propósito de reflejar la triste condición espiritual de su personaje. Para concluir, en mi lectura el texto de García Márquez es de naturaleza ligera, muy placentero de leer y a la vez carente de la densa exploración psicológica conseguida por Kawabata en el suyo.

\section{Obras citadas}

García MÁRQueZ, Gabriel. 2004. Memoria de mis putas tristes. Nueva York: Vintage Español, Vintage Books.

Gessel, Van C. y Tomote Matsumoto, eds. 1992. The Showa Anthology: Modern Japanese Short Stories. Tokio: Kodansha Internacional.

KaWABATA, Yasunari. 1985. La casa de las bellas durmientes. Traducción de Pilar GIRALT. Barcelona: Ediciones Orbis. (Col. Premios Nobel) 